\title{
Martial Arts-Based Therapy Reduces Pain and Distress Among Children with Chronic Health Conditions and Their Siblings
}

This article was published in the following Dove Press journal: Journal of Pain Research

\author{
Hilary A Marusak $\mathbb{D}^{1-3}$ \\ Allesandra S ladipaolo ${ }^{4}$ \\ Cindy Cohen ${ }^{5}$ \\ Elimelech Goldberg ${ }^{5,6}$ \\ Jeffrey W Taub ${ }^{6,7}$ \\ Felicity WK Harper (D) $^{3,7}$ \\ Martin H Bluth $\mathbb{D}^{5,8}$ \\ Christine A Rabinak (D) 1,2,4,9 \\ 'Department of Psychiatry and \\ Behavioral Neurosciences, School of \\ Medicine, Wayne State University, \\ Detroit, MI, USA; ${ }^{2}$ Merrill Palmer \\ Skillman Institute, Wayne State \\ University, Detroit, MI, USA; ${ }^{3}$ Population \\ Studies and Disparities Research \\ Program, Karmanos Cancer Institute, \\ Detroit, MI, USA; ${ }^{4}$ Department of \\ Pharmacy Practice, Eugene Applebaum \\ College of Pharmacy and Health Sciences, \\ Wayne State University, Detroit, MI, \\ USA; ${ }^{5}$ Kids Kicking Cancer, Southfield, \\ MI, USA; ' ${ }^{6}$ epartment of Pediatrics, \\ School of Medicine, Wayne State \\ University, Detroit, MI, USA; \\ ${ }^{7}$ Department of Oncology, School of \\ Medicine, Wayne State University, \\ Detroit, MI, USA; ${ }^{8}$ Department of \\ Pathology, School of Medicine, Wayne \\ State University, Detroit, MI, USA; \\ ${ }^{9}$ Department of Pharmaceutical Sciences, \\ Eugene Applebaum College of Pharmacy \\ and Health Sciences, Wayne State \\ University, Detroit, MI, USA
}

Objective: Test whether a martial arts-based therapy, Kids Kicking Cancer (KKC), can reduce pain and emotional distress in children with cancer, other chronic health conditions (e.g., sickle cell), and healthy siblings.

Methods: This study surveyed children's pain and distress levels immediately before and after a 1-hr in-person KKC class. Eligible participants were enrolled in standard KKC classes, were diagnosed with a chronic health condition (e.g., cancer, sickle cell) or were the sibling of a child diagnosed and were between the ages of 5-17 years (inclusive). Children reported on their pain and distress using Likert-style scales (Coloured Analog Scale and modified FACES scale, respectively). Friedman test was used to test for overall changes in pain and distress, and within subgroups. Age and sex effects were evaluated using Spearman's rank-order correlation. Additional Yes/No questions were administered regarding KKC satisfaction and use of techniques.

Results: Fifty-nine youth (19 cancer patients, 17 non-cancer patients, 23 siblings; 5-17 yrs, 26 females) completed this study. Overall, there was a significant reduction in pain ( $p=$ $0.033)$ and emotional distress $(p<0.001)$ after a 1-hr class, with $50 \%$ and $89 \%$ of youth reporting a reduction in pain and distress, respectively. On average, pain levels remained within the mild/moderate range on average (i.e., pre vs. post levels; pre: $M=1.67$, post: $M=$ 1.33 ) and emotional distress went from mild/moderate to none/mild distress, on average (pre: $\mathrm{M}=1.92$, post: $\mathrm{M}=1.08$ ). Youth with higher pre-class pain and distress reported greater reductions ( $p=0.001$ and $p<0.001$, respectively). The reduction in pain appeared to be most pronounced with cancer and non-cancer patients. In contrast, the reduction in distress appeared to be most pronounced among healthy siblings. However, overall, reductions in pain and distress did not significantly differ among subgroups (i.e., cancer patients, noncancer patients, siblings), and change in pain and distress was not associated with age or sex. Ninety-six percent of youth would recommend KKC to others and $81 \%$ reported using KKC techniques (e.g., the Breath Brake ${ }^{\mathrm{TM}}$ or other martial arts techniques) outside of class, such as at home.

Conclusion: Results support the more widespread application of $\mathrm{KKC}$ as a psychosocial intervention for reducing pain and distress in various pediatric populations.

Keywords: meditation, mindfulness, oncology, psychosocial, sickle cell, leukemia

\section{Plain Language Summary}

About one in four of children and adolescents in the United States have a chronic health condition, such as asthma, cancer, or diabetes. Childhood chronic health conditions and their associated treatments can be painful and emotionally distressing for children and their families,

Tel +I 313-577-1278

Fax +1 313-577-6188

Email hmarusak@med.wayne.edu 
and under or untreated pain or distress in childhood can negatively impact daily functioning and long-term outcomes. Siblings of children with chronic health conditions are also are at increased risk of experiencing pain and distress themselves. This study tested whether a martial arts-based therapy, Kids Kicking Cancer, can reduce pain and emotional distress in children with cancer, other chronic health conditions (e.g., sickle cell), and healthy siblings. The researchers found that a 1-hr Kids Kicking Cancer class reduces pain and emotional distress in children and $96 \%$ of children would recommend Kids Kicking Cancer to other children. Martial arts-based therapies such as Kids Kicking Cancer may be helpful for reducing pain and emotional distress among children with chronic health conditions and siblings.

\section{Introduction}

Globally, more than 300,000 children are diagnosed with cancer each year. ${ }^{1}$ Another 300,000 children across the globe are born with severe hemoglobin disorders (e.g., sickle cell anemia) each year, ${ }^{2}$ and many more live with other chronic- or life-threatening childhood health conditions, such as asthma, cystic fibrosis, hemophilia, and diabetes. The prevalence of chronic health conditions among children has increased over the past few decades, ${ }^{3,4}$ and these conditions cause significant societal and individual burden. ${ }^{5}$ Children with chronic health conditions and their families face enormous psychological stressors, which can disrupt daily life, impair social functioning and academic performance, and reduce overall quality of life for multiple family members. ${ }^{6}$

Childhood chronic health conditions and their associated treatments can be painful and emotionally distressing. Estimated rates of emotion-related psychological impairment (e.g., depression, anxiety, posttraumatic stress symptoms) among children with chronic illnesses range from $24 \%$ to $88 \% .^{7-12}$ Children's distress reactions to treatment may cause difficulty in regulating pain, which many children with chronic illness experience at some point during the disease or its treatment. ${ }^{13}$ Pain in the context of childhood chronic illness can be secondary to treatment procedures (e.g., bone marrow aspirations, intramuscular/intravenous injections), due to the disease itself (e.g., vaso-occlusive crisis), or side effects of treatment (e.g., postoperative pain, neuropathic pain). ${ }^{13}$ Together, pain and emotional distress are prevalent among children with and without chronic health conditions and can negatively impact daily functioning and long-term outcomes.

Under or un-treated pain and distress during childhood and adolescence increases risk of later impairment. Studies show that as many as $73 \%$ of children and adolescents with chronic pain will continue to have pain in adulthood or develop new pain conditions. ${ }^{14,15}$ Pediatric patients with chronic pain are also at an almost five times greater risk of lifetime anxiety disorder. ${ }^{16}$ Pain and distress that lingers into adulthood is associated with disability, comorbid cognitive and emotion-related problems (e.g., anxiety, depression), and diminished work productivity. ${ }^{17}$ Inadequate management of pain and emotional distress in childhood can lead to increased healthcare usage, reduced adherence to treatment procedures, morbidity, and even mortality. Further, pediatric chronic pain is associated with enormous economic burden, including an estimated $\$ 19.5$ billion/year in the US due to healthcare costs, lost employment, and out-of-pocket expenses. ${ }^{18}$ Thus, pediatric pain and emotional distress are significant public health concerns, throughout the lifespan.

Given the high prevalence and adverse effects of pediatric pain and emotional distress, there is a critical need for effective interventions. Existing evidence-based interventions for pediatric pain and distress include both pharmacological and non-pharmacological approaches, such as cognitive-behavioral approaches, mindfulness-based approaches, and medications (e.g., opioids, selective serotonin reuptake inhibitors [SSRIs]). ${ }^{19,20}$ More comprehensive approaches that integrate both medical and psychosocial interventions may be more effective than usual care for reducing current pain and distress and reducing the risk of continued impairment into adulthood. ${ }^{21}$ Compared to usual care, more comprehensive approaches to addressing pediatric pain and address can also reduce healthcare costs. For example, such integrated treatment programs have been shown to save an estimated US $\$ 27,199 /$ year per family, ${ }^{22}$ and free up physician time to see $42 \%$ more patients, generating an additional US\$1142/ day in revenue in pediatric clinics. ${ }^{23}$ However, access to evidence-based psychosocial support for children with chronic health conditions throughout the disease trajectory (e.g., diagnosis through survivorship) is limited. ${ }^{24}$

Kids Kicking Cancer (KKC, https://kidskickingcancer. org) is an international organization that provides martial artsbased therapy for children with cancer, other chronic illnesses, as well as, healthy siblings, as a part of the "Heroes Circle" program. Now embedded in more than 90 children's hospitals and other locations in seven countries (US, Italy, Israel, Canada, South Africa, Zambia, Zimbabwe), KKC provides psychosocial support, social interaction, procedure preparation, and sibling support - which are specific areas of need 
highlighted by the Standards for Psychosocial Care for Children with Cancer and their Families. ${ }^{24}$ KKC uses martial arts-based techniques including meditations, breathing, and specific empowering movements to help children learn to cope with the pain and distress of their disease and/or its treatment. Such mindfulness-based approaches have been previously shown to be effective for reducing pain and improving mental health among children and adolescents. ${ }^{20,25}$ However, $\mathrm{KKC}$ is unique in that it is a martial arts-based therapy that pairs meditation and mindfulness approaches with physical movement and themes of purpose and empowerment, which may have additional benefit. ${ }^{26,27}$

Another unique aspect of $\mathrm{KKC}$ is that programming includes healthy siblings who, although often part of the healthcare management of the patient, are increasingly recognized as a psychologically at-risk group themselves. ${ }^{28,29}$ Research shows that siblings of children with chronic pain are at increased risk of experiencing pain themselves, as compared to their non-sibling peers. ${ }^{30}$ Further, research on siblings of children with cancer indicate that a significant subset experience posttraumatic stress symptoms, negative emotional reactions (e.g., fear, worry, sadness, anger), and poor quality of life. ${ }^{28}$ Siblings may also experience pain or distress vicariously, ${ }^{31}$ as a result of seeing their brother or sister in pain or distress, or distress associated with bereavement. ${ }^{32}$ Pain and emotional distress are also prevalent among nonsibling, nonclinical populations. Approximately one-quarter to one-third of children and adolescents experience chronic pain (e.g., headache, abdominal pain) ${ }^{33}$ and about one-third of youth are affected by an anxiety disorder. ${ }^{34}$ Given the increased risk of poor psychosocial adjustment, prior research has highlighted the need for interventions that include siblings of children with chronic illness. ${ }^{35}$

We previously reported that a 1-hr KKC session can reduce pain among children with cancer, with $85.3 \%$ reporting a reduction in pain. ${ }^{27}$ Using an independent sample, the present study aims to extend this prior important work to children with other chronic health conditions, as well as, healthy siblings - populations that can experience significant pain and emotional distress. We also extend the prior study by measuring emotional distress, in addition to pain.

\section{Method}

\section{Participants}

This study reports on 59 children and adolescents, ages 5-17 years $($ median $=10.37$ years; 26 females). Eligible participants were enrolled in a standard KKC class, were diagnosed with a chronic childhood health condition or were a sibling, and were between the ages of 5-17 (inclusive). Children younger than age 5 were excluded to enhance reliability of pain and distress ratings. Classes were held at the KKC Southfield, Michigan location (Metro Detroit) and thus outside of the hospital setting. The majority of participants at the KKC Southfield location are recruited through healthcare providers (e.g., social workers, oncologists) at the Children's Hospital of Michigan (Detroit, Michigan), or from word-of-mouth. Sixty-one percent $(n=36)$ of participants were patients, and the remaining $39 \%$ were siblings $(n=23)$. Of the children who were patients, $52.8 \%(\mathrm{n}=19)$ had cancer diagnoses, including acute lymphoblastic leukemia (ALL), neuroblastoma, and brain tumor (see Table 1). Seventeen children had non-cancer chronic illnesses, such as sickle cell, hemophilia, asthma, chronic pain, and diabetes. Overall demographic data, and demographic data by subgroup (i.e., cancer patients, non-cancer patients, healthy siblings), are given in Table 1. Age and sex distribution did not differ between cancer and non-cancer patients, or among the three subgroups (i.e., cancer patients, noncancer patients, healthy siblings; $p>0.05$ ). This study was carried out as a secondary analysis of collected data for the internal evaluation of KKC programming. Data were therefore limited with regard to how many siblings were related to patients in this sample, details of individual participant recruitment, detailed medical history (e.g., treatment type, dosage), and current patient status (e.g., active treatment, survivorship). All data accessed complied with relevant data protection and privacy regulations and were maintained with confidentiality. The study procedures were approved by the Wayne State University Institutional Review Board.

\section{Kids Kicking Cancer Classes}

$\mathrm{KKC}$ classes usually include a mix of children with cancer, non-cancer chronic health conditions, and healthy siblings. Classes are taught by specially trained black beltlevel martial arts therapists, and its mantra is "Power, Peace, Purpose", which is intended to imbue the participant with self-control, awareness, and a feeling of empowerment. Classes also provide a unique platform for students to interact with peers undergoing similar experiences and allow students to learn and share how martial arts techniques can be used to overcome daily challenges (e.g., disease-related or other daily stressors). For example, the KKC "Ninja Needle" technique was developed to help 
Table I Participant Demographics

\begin{tabular}{|c|c|c|}
\hline Overall $(N=59)$ & $\mathbf{n}$ & $\%$ \\
\hline \multicolumn{3}{|l|}{ Sex } \\
\hline Female & 26 & 44.1 \\
\hline Male & 33 & 55.9 \\
\hline \multicolumn{3}{|l|}{ Subgroup } \\
\hline Cancer patients & 19 & $32 \%$ \\
\hline Non-cancer patients & 17 & $29 \%$ \\
\hline Healthy siblings & 23 & $39 \%$ \\
\hline \multirow[b]{2}{*}{ Age (years) } & M & SD \\
\hline & 10.1 & 2.8 \\
\hline Cancer Patients $(n=19)$ & $\mathbf{n}$ & $\%$ \\
\hline \multicolumn{3}{|l|}{ Sex } \\
\hline Female & 7 & $37 \%$ \\
\hline Male & 12 & $63 \%$ \\
\hline \multicolumn{3}{|l|}{ Diagnosis } \\
\hline Acute lymphoblastic leukemia & II & 30.6 \\
\hline Brain tumor & 2 & 5.6 \\
\hline Neuroblastoma & 2 & 5.6 \\
\hline Neurofibromatosis & I & 2.8 \\
\hline Osteosarcoma & I & 2.8 \\
\hline Rhabdomyosarcoma & 1 & 2.8 \\
\hline Not specified & I & 2.8 \\
\hline \multirow[b]{2}{*}{ Age (years) } & M & SD \\
\hline & 10.6 & 2.7 \\
\hline Non-Cancer Patients $(n=17)$ & $\mathbf{n}$ & $\%$ \\
\hline \multicolumn{3}{|l|}{ Sex } \\
\hline Female & 9 & $53 \%$ \\
\hline Male & 8 & $47 \%$ \\
\hline Diagnosis & 17 & 47.2 \\
\hline Sickle cell & 7 & 19.4 \\
\hline Hemophilia & 4 & II.I \\
\hline Pain clinic & I & 2.8 \\
\hline Asthma & I & 2.8 \\
\hline Diabetes & I & 2.8 \\
\hline Chiari Malformation & I & 2.8 \\
\hline Other hematological disorder & I & 2.8 \\
\hline Nephrotic syndrome & 1 & 2.8 \\
\hline \multirow[b]{2}{*}{ Age (years) } & $M$ & SD \\
\hline & 10.7 & 2.8 \\
\hline Healthy Siblings $(n=23)$ & $\mathbf{n}$ & $\%$ \\
\hline \multicolumn{3}{|l|}{ Sex } \\
\hline Female & 10 & 56.5 \\
\hline Male & 13 & 43.5 \\
\hline \multirow[b]{2}{*}{ Age (years) } & M & SD \\
\hline & 9.1 & 2.9 \\
\hline
\end{tabular}

children cope with needle-related procedures, such as venipunctures. KKC martial arts therapists are also integrated into several hospital systems and provide bedside support and interventions to help children cope with treatment-related procedures in real-time.

A standard KKC class begins with the mantra "Power. Peace. Purpose." and is followed by a deep breathing exercise (Breath Brake $^{\mathrm{TM}}$ ), consisting of breathing in, holding the breath and breathing out at 3 to 4 second intervals each and an introspective body-scan led by specially trained martial arts therapists. A series of moving meditations are then taught, including kicks and punches, and movements are tailored based on physical abilities and clinical indications of the child. There is no physical contact (e.g., sparring) during sessions. During the class, the martial arts therapists may also teach certain specific techniques, e.g., the Ninja Needle technique for needle-related medical procedures, depending on class experience. Instructors also ask students how they used KKC techniques in their daily lives, for example, use of the Breath Brake $^{\mathrm{TM}}$ at home, school, or during treatment-related procedures. For more information on KKC techniques and standard class formats, see Bluth et al. ${ }^{27}$

\section{Procedure}

Participants prospectively reported on their pain and distress before and after a standard KKC class session, using brief surveys. Participants were assisted in completing these brief surveys by specially trained KKC martial arts therapists, staff, and/or volunteers. Surveys consisted of standardized Likert scales of pain and emotional distress (explained to children as "bad", "worried", or "anxious"). Pain was measured using the Coloured Analog Scale ${ }^{36}$ on a scale from 0 to 10 (where 0 is no pain and 10 is the worst possible pain). Distress was rated using an adapted version of the FACES scale $\left(\mathrm{see}^{37,38}\right.$ ) on a scale from 1 to 5 (where 1 is no distress and 5 is the worst possible distress). Following the class, students were also asked if they: (1) would recommend KKC to other children (yes/no), (2) felt like a powerful martial artist (yes/no), (3) practiced or used the Breath Brake ${ }^{\mathrm{TM}}$ at least once over the past week (yes/no), and (4) practiced or used other martial arts techniques at least once over the past week (yes/no). Students were asked whether or not they felt like a powerful martial artist given that the mantra of KKC is Power. Peace. Purpose., and students are taught to reframe themselves as a powerful martial artist who can face any life challenge rather than a victim of their experience. Power 
emanates from introducing an expanded element of control of one's situation. The mind-body movements coalesce to move the individual from passive acceptance of one's predicament to active engagement toward change. Peace derives from acceptance of one's current situation and can mitigate negative feelings that often create behavioral stagnation. Purpose introduces elements of conviction and positive value for one's existence and situation. It can help to transcend one's situation and transform benign activity into something greater than the sum of its parts.

\section{Data Analysis}

Responses on the pain and distress Likert scales showed positive skew, with only $11.2 \%$ of responses exceeding 2 for pain levels and only $12 \%$ of responses exceeding 2 for distress. To reduce the skew in the data, we recoded the data to increase the frequency within response categories by collapsing across categories. In particular, pain and distress scores were recoded as follows: $0=$ no pain or distress, $1=$ mild pain or distress, $2=$ moderate pain or distress, and $3=$ severe pain or distress. Of note, post-class pain level was missing from one participant (hemophilia patient), and post-class distress rating was missing from one participant (cancer patient).

Analyses were first performed across the entire sample (i.e., overall; $\mathrm{N}=59$ ), and then within the largest subgroups separately: (1) cancer patients, (2) non-cancer patients, and (3) healthy siblings. We included siblings in the overall analysis given that siblings are also at increased risk of pain and emotional distress. ${ }^{28,39,40}$ First, we quantified the number of children who reported pre-class pain or emotional distress (i.e., scores $>0$ ). Next, for those who reported pre-class pain or distress $(>0)$, we quantified the number of children who reported an increase, decrease, or no change in pain or distress over the course of the 1-hr class session. Then, to test whether observed changes reached statistical significance, we used non-parametric Friedman's two-way analysis of variance by ranks to compare pain and distress scores reported before vs. after class. All results were considered significant at a $p<0.05$ (two-tailed) threshold and utilized the recoded data. Spearman's rank-order correlation was used to test whether pre-class pain or distress was correlated with the change score (pre-post) in pain or distress. Spearman's rank-order correlation was also used to test whether age and sex were associated with levels of pre-class pain or distress or change (pre-post) in pain or distress. Statistical analyses were performed in SPSS Software version 26
(IBM Corporation). For the additional questions regarding KKC satisfaction and use of techniques, "Yes" and "No" responses to each question were quantified across the entire sample, and for each subgroup separately (i.e., cancer patients, non-cancer patients, healthy siblings).

\section{Results \\ Pain Overall}

Across all children, 41\% reported at least some pain (i.e., scores $>0$ ) before the class session. Age and sex were not associated with pre-class pain $(p>0.05)$. Of the children who reported no pre-class pain $(\mathrm{n}=34)$, three $(9 \%)$ reported mild pain at the post-class time point ( 1 cancer patient, 1 non-cancer patient, and 1 sibling). Overall, for those reporting pre-session pain $(>0), 50 \%$ of children reported a reduction in pain, 37\% reported no change in pain, and $8 \%$ reported an increase in pain. See Figure $1 \mathrm{~A}$ for distribution of pre- and post-class pain, by group. For those who reported pre-class pain, there was a significant reduction in pain (i.e., pre vs. post levels; pre: $\mathrm{M}=1.67$, post: $\mathrm{M}=1.33, \chi^{2}(1)=4.57, p=0.033$ ) and pain levels remained within the mild/moderate range on average (Figure 2). Change in pain scores (i.e., pre-post) did not significantly differ by group (cancer patients, non-cancer patients, siblings; $p>0.2$ ). For those reporting pre-class pain, age and sex were not associated with change in pain scores (i.e., pre-post; $r_{s}=-0.03, p=0.82$ and $r_{s}=0.12$, $p=0.38$, respectively). Higher pre-class pain, was however, associated with a greater reduction in pain $\left(r_{s}=0.42\right.$, $p=0.001)$.

\section{Cancer Patients}

Pre-session pain $(>0)$ was reported by $42 \%$ of cancer patients. For cancer patients who reported pre-session pain, 37\% reported a reduction in pain, 63\% reported no change in pain, and no cancer patients reported in increase in pain. Pre- and post-class pain levels were $\mathrm{M}=1.69$ and $\mathrm{M}=1.31$, respectively, among cancer patients, $\chi^{2}(1)=3$, $p=0.08$.

\section{Non-Cancer Patients}

Pre-session pain $(>0)$ was reported by $53 \%$ of non-cancer patients. For non-cancer patients who reported pre-session pain, $78 \%$ reported a reduction in pain, $22 \%$ reported no change in pain, and no non-cancer patients reported in increase in pain. The overall reduction in pain appeared to be most pronounced among non-cancer patients, with 
A

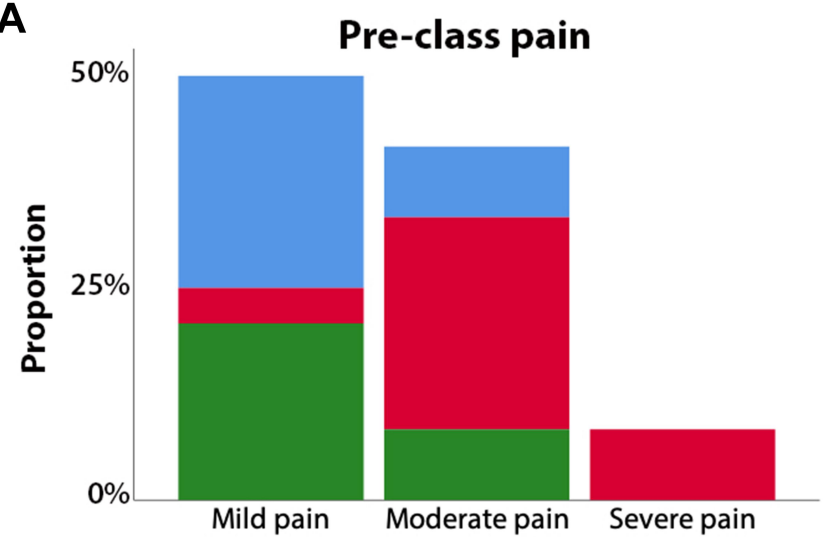

B

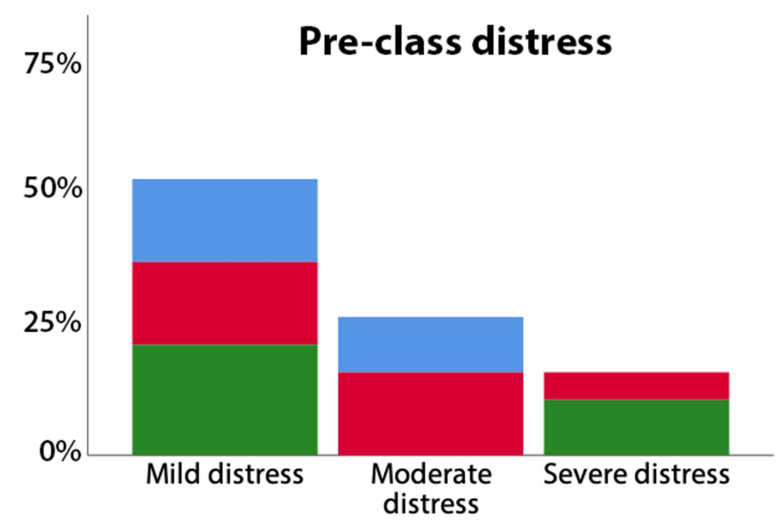

\section{Post-class pain}
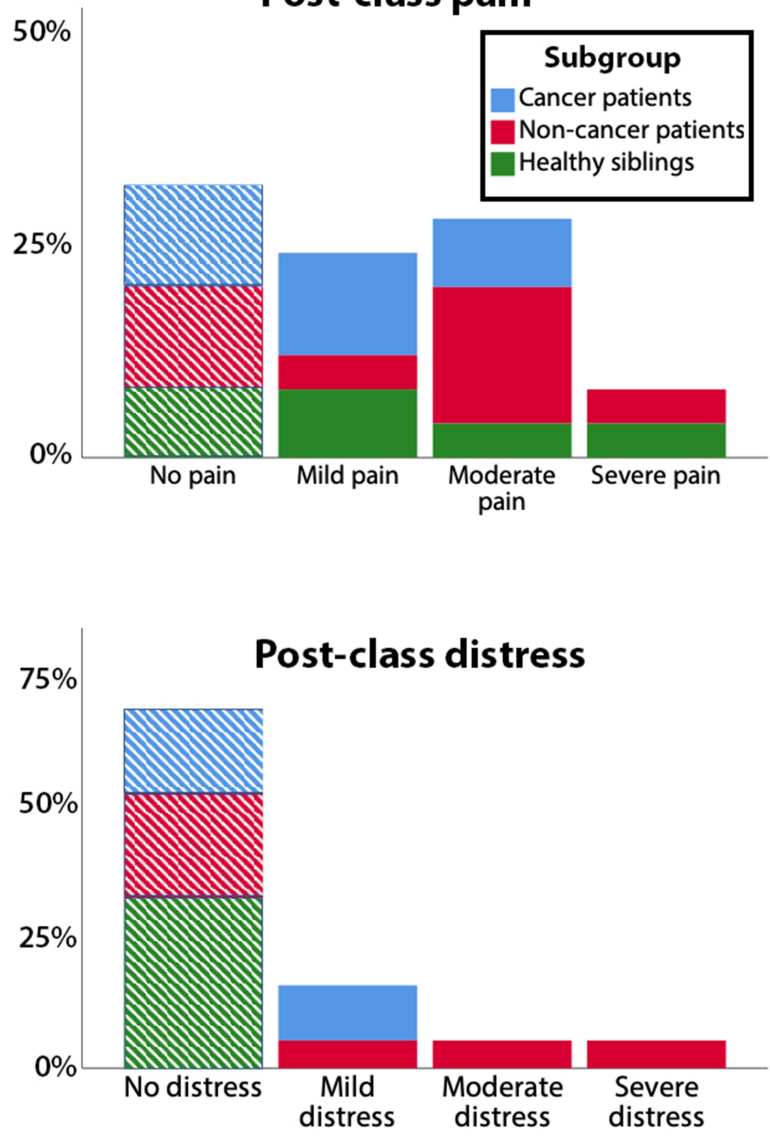

Figure I Distribution of pre- and post-class pain (A) and emotional distress (B), by group. Top row (panel (A)) indicates pre- and post-class pain. Bottom row (panel (B)) indicates pre- and post-class distress. The vertical axis indicates the portion of participants who reported pain or distress in each category. Only participants are shown who reported pre-class pain or distress ( $>0 ; \mathrm{N}=24$ for pain, $\mathrm{N}=18$ for distress). Dashed bars indicate participants who reported no post-class pain or distress. Of note, postclass pain rating was missing for one participant (hemophilia patient), and post-class distress rating was missing for one participant (cancer patient).

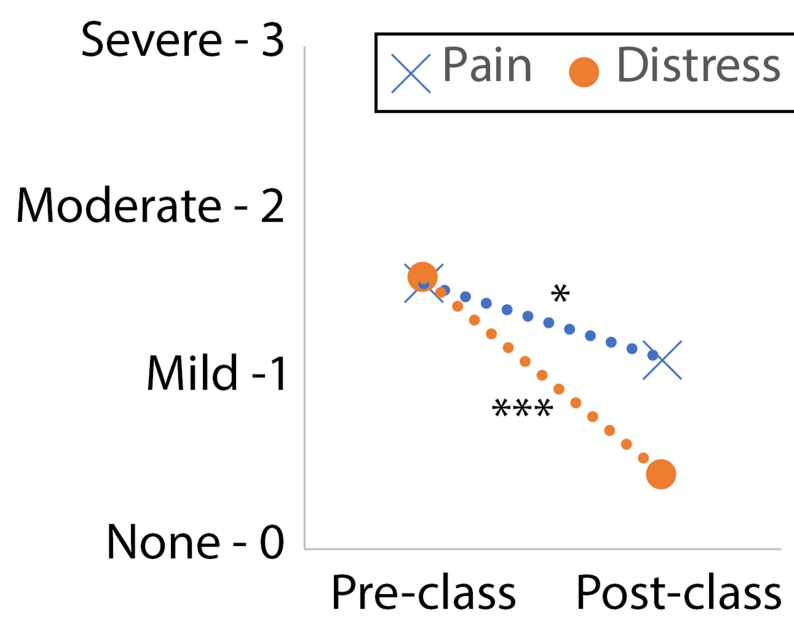

Figure 2 Significant reduction in pain and distress over the course of one class. Overall average of pre- and post-class pain and emotional distress. ${ }^{*} p<0.05$, ${ }^{* * *} p<$ 0.001 . pre- and post-class pain levels of $\mathrm{M}=1.78$ and $\mathrm{M}=1.22$, respectively, $\chi^{2}(1)=3.57, p=0.06$.

\section{Siblings}

Pre-session pain $(>0)$ was reported by $30 \%$ of healthy siblings. For siblings who reported pre-session pain, 33\% reported a reduction in pain, 33\% reported no change in pain, and 33\% reported in increase in pain. Pre- and postclass pain levels did not differ among healthy siblings (pre: $\mathrm{M}=1.5$, post: $\mathrm{M}=1.5$ ).

\section{Emotional Distress Overall}

Across all children, 31\% reported at least some distress (i.e., scores $>0$ ) before the class session. Age and sex were not associated with pre-class distress $(p>0.05)$. Of 
the children who reported no pre-class distress $(n=34)$, two $(6 \%)$ reported mild distress at the post-class time point (1 cancer patient, 1 sibling). Overall, for those reporting pre-session distress $(>0), 89 \%$ of children reported a reduction in distress, $6 \%$ reported no change in distress, and $6 \%$ reported an increase in distress. See Figure $1 \mathrm{~B}$ for distribution of pre- and post-class distress, by group. For those who reported pre-class distress, there was a significant reduction in distress (i.e., pre vs. post levels; pre: $\mathrm{M}=1.92$, post: $\left.\mathrm{M}=1.08, \chi^{2}(1)=13.24, p<0.001\right)$, and went from mild/moderate distress to none/mild distress (Figure 2). The change in distress scores (i.e., prepost) did not significantly differ by group (cancer patients, non-cancer patients, siblings; $p>0.7$ ). For those reporting pre-class distress, age and sex were not associated with change in distress scores (i.e., pre-post; $r_{s}=0.057, p=$ 0.68 and $r_{s}=-0.11, p=0.43$, respectively). Higher preclass distress, was however, associated with a greater reduction in distress $\left(r_{s}=0.78, p<0.001\right)$.

\section{Cancer Patients}

Pre-session distress $(>0)$ was reported by $26 \%$ of cancer patients. For cancer patients who reported pre-session distress, $80 \%$ reported a reduction in distress, $20 \%$ reported no change in distress, and no cancer patients reported in increase in distress. Pre- and post-class distress was $\mathrm{M}=1.9$ and $\mathrm{M}=$ 1.1 , respectively, among cancer patients, $\chi^{2}(1)=4, p=0.046$.

\section{Non-Cancer Patients}

Pre-session distress $(>0)$ was reported by $41 \%$ of noncancer patients. For non-cancer patients who reported presession distress, $86 \%$ reported a reduction in distress, no non-cancer patients reported no change in distress, and $14 \%$ reported in increase in distress. Pre- and post-class distress was $\mathrm{M}=1.86$ and $\mathrm{M}=1.14$, respectively, among non-cancer patients, $\chi^{2}(1)=3.57, p=0.06$.

\section{Siblings}

Pre-session distress $(>0)$ was reported by $26 \%$ of healthy siblings. For siblings who reported pre-session distress, $100 \%$ reported a reduction in distress. The overall reduction in distress appeared to be most pronounced among healthy siblings, with pre- and post-class distress ratings of $\mathrm{M}=2$ and $\mathrm{M}=1$, respectively, $\chi^{2}(1)=6, p=0.014$.

\section{Satisfaction and Use of KKC Techniques}

Overall, $96 \%$ of children responded "Yes" to the Yes/No question "Would you recommend KKC to other children?" and $82 \%$ responded "Yes" to the Yes/No question "Do you feel like a powerful martial artist?". Further, $81 \%$ reported using the Breath Brake ${ }^{\mathrm{TM}}$ at least once over the past week, and $76 \%$ reported using martial arts techniques at least once outside of class over the past week. Distribution of yes/no responses for each question did not significantly differ by age, sex, or subgroup $(p>0.05)$.

\section{Discussion}

These results demonstrate that martial arts-based therapy may be an effective psychosocial intervention for reducing pain and emotional distress among children with cancer, non-cancer chronic childhood health conditions (e.g., sickle cell, diabetes), and healthy siblings. Overall, 50\% and $89 \%$ of children reported a reduction in pain and emotional distress, respectively, after a 1-hr KKC class. Although change in pain or distress scores did not significantly differ among subgroups (cancer patients, noncancer patients, siblings), pre-class pain was more prevalent among cancer and non-cancer patient subgroups relative to siblings, and accordingly, the reduction in pain appeared to be more pronounced among cancer and noncancer patients as compared to siblings. Although preclass emotional distress was common across subgroups (i.e., cancer patients, non-cancer patients, siblings), the reduction in emotional distress appeared to be most pronounced among siblings. The reduction in emotional distress among siblings is important because siblings are increasingly recognized as a psychologically at-risk group. ${ }^{28}$ Importantly, the KKC program was highly agreeable among children, with $96 \%$ reporting that they would recommend $\mathrm{KKC}$ to other children. Eighty-two percent reported feeling like a martial artist and $81 \%$ reported that they used the Breath Brake ${ }^{\mathrm{TM} 27}$ outside of class, suggesting that these techniques may be helpful for coping with every day and disease-related stressors. Change in pain or emotional distress and satisfaction with $\mathrm{KKC}$ did not differ by age, sex, or subgroup. Taken together, these data add to the growing evidence base supporting the use of martial arts-based therapy for the management of pediatric pain and distress. ${ }^{27}$

More than half $(59 \%)$ of patients in the present sample reported a reduction in pain over the course of a 1-hr KKC class session. The proportion reporting a reduction in pain was lower than observed in our previous study in pediatric cancer patients, ${ }^{27}$ with $85 \%$ reporting a reduction in pain. Although detailed medical history (e.g., treatment type, dosage) and current status (e.g., active treatment, survivorship) was not collected in this study, the different rates 
may be due to heterogeneity in patient age, disease state, and/or treatment history. In particular, the age range of the present sample was 5-17 years whereas our prior study (Bluth et $\mathrm{al}^{27}$ ) was 3-19 years. Importantly, in our prior study, ${ }^{27}$ the greatest reduction in pediatric cancer pain was reported among older youth (e.g., 15-19 years) whereas there was a relatively limited number of older children (i.e., only two children were $\geq 15$ years) in the present sample. In addition, in both studies, pain was measured outside of the hospital setting and thus we did not anticipate a large number of children in acute pain. Future research should test whether KKC martial arts techniques are effective at reducing pain and distress during treatment-related procedures (e.g., port-starts). KKC martial arts therapists are already integrated into approximately 90 hospital and/or healthcare-related systems across the globe and provide bedside support and interventions to help children cope with treatment-related procedures in real-time. For example, martial arts therapists guide children through breathing and meditation exercises (e.g., the Breath $\mathrm{Brake}^{\mathrm{TM}}$ ) during treatment procedures, including the specialized KKC "Ninja Needle" technique which was developed to help children cope with needle-related procedures. Larger prospective studies are needed to examine the longer-term effects of single versus multiple sessions, and of various disease states and indications.

Children with chronic health conditions often experience fear, emotional distress, and worry regarding death, feelings of separation from their friends and family, and recurring social confinement in the hospital. ${ }^{41}$ Distress can contribute to anxiety, depression, and posttraumatic stress symptoms. ${ }^{42}$ Fear, anxiety, and emotional distress in these pediatric populations can lead to a range of poor outcomes, including avoidance of subsequent medical monitoring, ${ }^{43}$ reduced adherence to treatments, poorer quality of life, ${ }^{44}$ and increased pain sensitivity. ${ }^{45}$ Emotional distress can also exacerbate medical-related adverse events, such as precipitation of vaso-occlusive crisis in sickle cell disease. ${ }^{46}$ Our data suggest that a $1-\mathrm{hr}$ KKC session can reduce emotional distress among children with cancer, other chronic childhood health conditions, as well as, healthy siblings. Future research should examine whether there are longer-term benefits of KKC participation (i.e., beyond a single session) and whether the observed reductions in pain and distress are clinically meaningful. However, preliminary results from a school-based martial arts KKC program suggest that positive effects of martial arts training are sustained over five months postintervention (Marusak et al, under review).

Notably, children who reported higher pre-class pain and/or distress showed greater reductions over the course of the 1-hr KKC class. These results are consistent with those reported by Bluth et $\mathrm{al}^{27}$ and suggest a potential indication (e.g., high pain or distress ratings) for referral to KKC by social workers or other psychosocial support staff (e.g., Child Life Specialists). Nonetheless, children who are not experiencing acute pain or distress may also benefit from learning martial arts under the KKC program or other venues, as these techniques can help them cope with everyday challenges, including stressors associated with medical-related treatments, school, peers, or home life. Children may also benefit from the opportunity to interact with peers who are going through similar experiences, as prior research indicates that social relationships predict better adjustment to pediatric cancer. ${ }^{47}$ Importantly, across both studies, there was no effect of sex on reductions in pain, and in this study, distress. The present study also adds that change in pain or emotional distress and satisfaction with KKC does not differ by sex or subgroup. Taken together, these results replicate and extend our prior work by including a wider range of pediatric populations (non-cancer patients, healthy siblings) and an assessment of emotional distress.

The observed significant reduction in emotional distress among healthy siblings is important because siblings are often not included in psychosocial care; yet, siblings frequently experience distress related to the sick child's wellbeing, changes in family dynamics and daily routines, feelings of social exclusion, and even rivalry for parental attention. ${ }^{48}$ Among childhood cancer families, siblings report lower quality of life and higher rates of anxiety, depression, and social withdrawal as compared to nonsibling controls. ${ }^{49}$ Consistent with these data, about a quarter of siblings reported pre-class emotional distress in this study. Martial arts techniques may be beneficial for helping siblings to cope with stressors associated with having a child with chronic illness in the family, as well as, with everyday stressors (e.g., schoolwork, peer and family conflicts). Inclusion of siblings together with patients in KKC classes may promote adjustment of the entire family, as social support, family togetherness, and family cohesion have been shown to predict better adjustment among both pediatric patients and siblings. ${ }^{49,50}$

Almost one-third of siblings in the present study reported pre-class pain. This is consistent with prior 
studies $^{51-53}$ reporting that $15-35 \%$ of children in a nonclinical population experience persistent or chronic pain (e.g., headache, neck and shoulder pain, abdominal pain). One recent survey study of over 1000 children and adolescents (ages 8-18 yrs) found that $60 \%$ reported pain within the past three months, and that higher pain was associated with lower health-related quality of life. ${ }^{54}$ Together, these findings suggest that pain problems are common and can have negative impacts on life (e.g., mood, relationships, school functioning), even in a nonclinical population. Siblings of children with a chronic pain or chronic health conditions may be at an even higher risk of developing a pain condition themselves. For example, a subset of healthy siblings of children with functional abdominal pain also report abdominal pain and overall, ${ }^{30}$ siblings of children with chronic health conditions are at greater risk of developing somatic symptoms (e.g., headaches, fatigue) as compared to their peers. ${ }^{39,40}$ Siblings may also have vicarious experiences of contagious and empathetic pain, ${ }^{31}$ or experience pain and distress associated with bereavement. ${ }^{32}$ Together, these findings are consistent with a growing body research showing that a sibling's experience of pain or illness can affect children's functioning in several domains, including emotional, family, social, and school difficulties. ${ }^{28}$

\section{Study Limitations}

Child self-reports of pain and distress can be unreliable. However, children were assisted in filling out the surveys and child-friendly language was used (e.g., "bad", "worried", "anxious"). In addition, we selected measures that have been validated for use in children ages $5+{ }^{36-38}$ Although we examined effects of age, sex, and subgroup on changes in pain and distress, the study design and relatively limited sample size precluded further exploration of additional predictive variables (e.g., particular diagnoses, treatments, disease stage). This study was not designed as a randomized controlled trial, but rather was a secondary analysis of prospective data collected as a part of an internal program evaluation. Larger prospective studies are needed to identify baseline factors that predict greater response to $\mathrm{KKC}$, and to test longer-term effects. Similarly, larger "dismantling" studies are needed to identify the most effective therapeutic components of the KKC class (e.g., social interaction, Breath Brake ${ }^{\mathrm{TM}}$ ) against a control arm (e.g., waitlist).
The relatively limited sample size of subgroups and heterogeneity in terms of age and diagnosis restricted our ability to test for factors that may predict response to martial arts-based therapy. We attempted to examine the impact of this variability by testing for effects of age and testing for overall effects, and effects within our largest subgroups (i.e., cancer, non-cancer patients). Nonetheless, it is encouraging that, despite this heterogeneity, we found an overall reduction in pain and emotional distress following a 1-hr martial arts-based session, which suggests that martial arts-based therapy may be applicable to a wider range of pediatric populations. These observed significant effects may be even stronger in a larger sample size, particularly within a more homogeneous sample (e.g., ALL or sickle cell patients). This requires further study.

Another consideration is that $\mathrm{KKC}$ classes were not conducted in conjunction with medical-related procedures (e.g., bone marrow aspiration), and thus, many children reported little to no pain and/or distress prior to class. Nonetheless, for children who did report pre-class pain and/or distress, we observed significant reductions over the course of a 1-hr session. Many children with chronic health conditions do experience daily pain related to the disease itself, or side effects of treatment (e.g., nerve pain, mouth sores, neuropathic pain). The observation that a $\mathrm{KKC}$ intervention reduced pain and distress in siblings of children with chronic disease is compelling. Research by Deavin et $\mathrm{al}^{55}$ has demonstrated that siblings of children with chronic disease may have a suppression of their needs and reduced communication, which highlights the need for approaches to deal with such changes in family dynamics. To this end, KKC's beneficial effect many have important application to the wellbeing of the entire family unit. Future studies should assess whether the observed analgesic and anxiolytic effects of KKC are similarly observed or more pronounced during medicalrelated procedures for patients and the arborizing effect on siblings and other family members.

\section{Conclusion}

Together, the results of the present study suggest that martial arts-based therapy is effective for addressing the critical problem of pain and emotional distress among children with cancer, other chronic health conditions, and healthy siblings. Results support the more widespread application of $\mathrm{KKC}$ to a range of pediatric populations, including every day and medical-related stressors, including vaccinations and pediatric intensive care unit visits. 


\section{Abbreviations}

KKC, Kids Kicking Cancer; ALL, acute lymphoblastic leukemia.

\section{Acknowledgments}

Thank you to the children and families who shared their time to participate in the study, to Sajah Fakhoury, Kristopher Dulay, Rebecca Cramer, Autumm Heeter, Shelley Paulisin, for assistance with data collection, to Natalie Hardy for assistance with an earlier version of this manuscript, and to Richard Plowden, Marc Cohen, Peter Davenport, Michael Hunt, and Naami Kosofsky of Kids Kicking Cancer (KKC) for facilitating the KKC classes and questionnaire data collection.

\section{Funding}

This work was supported by a grant from the St. Baldrick's Foundation (523497) to HM. HM is supported by the National Institute of Mental Health (K01 MH119241). The grant providers had no influence on study design, the collection, analyses and interpretation of data, report writing nor decision of submission for publication.

\section{Disclosure}

The authors declare no conflicts of interest.

\section{References}

1. Steliarova-Foucher E, Colombet M, Ries LAG, et al. International incidence of childhood cancer, 2001-10: a population-based registry study. Lancet Oncol. 2017;18(6):719-731. doi:10.1016/S14702045(17)30186-9

2. Piel FB, Hay SI, Gupta S, Weatherall DJ, Williams TN, Osrin D. Global burden of sickle cell anaemia in children under five, 2010-2050: modelling based on demographics, excess mortality, and interventions. PLoS Med. 2013;10(7):e1001484. doi:10.1371/journal. pmed.1001484

3. Perrin JM, Bloom SR, Gortmaker SL. The increase of childhood chronic conditions in the United States. J Am Med Assoc. 2007;297 (24):2755. doi:10.1001/jama.297.24.2755

4. Van Cleave J, Gortmaker SL, Perrin JM. Dynamics of obesity and chronic health conditions among children and youth. JAMA. 2010. doi:10.1001/jama.2010.104

5. Miller GF, Coffield E, Leroy Z, Wallin R. Prevalence and costs of five chronic conditions in children. J Sch Nurs. 2016;32(5):357-364. doi:10.1177/1059840516641190

6. Compas BE, Jaser SS, Dunn MJ, Rodriguez EM. Coping with chronic illness in childhood and adolescence. Annu Rev Clin Psychol. 2012;8 (1):455-480. doi:10.1146/annurev-clinpsy-032511-143108

7. Kunin-Batson AS, Lu X, Balsamo L, et al. Prevalence and predictors of anxiety and depression after completion of chemotherapy for childhood acute lymphoblastic leukemia: a prospective longitudinal study. Cancer. 2016;122(10):1608-1617. doi:10.1002/cncr.29946
8. Hobbie WL, Stuber M, Meeske K, et al. Symptoms of posttraumatic stress in young adult survivors of childhood cancer. J Clin Oncol. 2000;18(24):4060-4066. doi:10.1200/JCO.2000.18.24.4060

9. Kazak AE. Posttraumatic Stress Disorder (PTSD) and Posttraumatic Stress Symptoms (PTSS) in families of adolescent childhood cancer survivors. J Pediatr Psychol. 2004;29(3):211-219. doi:10.1093/ jpepsy/jsh022

10. Erickson SJ, Steiner H. Trauma and personality correlates in long-term pediatric cancer survivors. Child Psychiatry Hum Dev. 2001;31(3):195-213. doi:10.1023/A:1026477321319

11. Schwartz LA, Kazak AE, Derosa BW, Hocking MC, Hobbie WL, Ginsberg JP. The role of beliefs in the relationship between health problems and posttraumatic stress in adolescent and young adult cancer survivors. J Clin Psychol Med Settings. 2012;19(2):138-146. doi:10.1007/s10880-011-9264-1

12. Szajnberg N, Krall V, Davis P, Treem J, Hyams J. Psychopathology and relationship measures in children with inflammatory bowel disease and their parents. Child Psychiatry Hum Dev. 1993;23 (3):215-232. doi:10.1007/BF00707151

13. Elliott SC, Miser AW, Dose AM, et al. Epidemiologic features of pain in pediatric cancer patients: a co-operative community-based study. North Central Cancer Treatment Group and mayo clinic). Clin J Pain. 1991;7(4):263-268. doi:10.1097/00002508-19911200000003

14. Walker LS, Dengler-Crish CM, Rippel S, Bruehl S. Functional abdominal pain in childhood and adolescence increases risk for chronic pain in adulthood. Pain. 2010;150(3):568-572. doi:10.1016/ j.pain.2010.06.018

15. Brna P, Dooley J, Gordon K, Dewan T. The prognosis of childhood headache: a 20-year follow-up. Arch Pediatr Adolesc Med. 2005;159 (12):1157. doi:10.1001/archpedi.159.12.1157

16. Shelby GD, Shirkey KC, Sherman AL, et al. Functional abdominal pain in childhood and long-term vulnerability to anxiety disorders. Pediatrics. 2013;132(3):475-482. doi:10.1542/peds.2012-2191

17. Mathews L. Pain in children: neglected, unaddressed and mismanaged. Indian J Palliat Care. 2011;17(4):70-73. doi:10.4103/ 0973-1075.76247

18. Groenewald CB, Essner BS, Wright D, Fesinmeyer MD, Palermo TM. The economic costs of chronic pain among a cohort of treatment-seeking adolescents in the United States. J Pain. 2014;15(9):925-933. doi:10.1016/j.jpain.2014.06.002

19. Simons LE, Basch MC. State of the art in biobehavioral approaches to the management of chronic pain in childhood. Pain Manag. 2016;6 (1):49-61. doi:10.2217/pmt.15.59

20. Groenewald CB, Beals-Erickson SE, Ralston-Wilson J, Rabbitts JA, Palermo TM. Complementary and alternative medicine use by children with pain in the United States. Acad Pediatr. 2017;17 (7):785-793. doi:10.1016/j.acap.2017.02.008

21. Martin SR, Zeltzer LK. Prioritizing pediatric chronic pain and comprehensive pain treatment in the context of the opioid epidemic. Pain Manag. 2018;8(2):67-70. doi:10.2217/pmt-2017-0072

22. Evans JR, Benore E, Banez GA. The cost-effectiveness of intensive interdisciplinary pediatric chronic pain rehabilitation. $J$ Pediatr Psychol. 2016;41(8):849-856. doi:10.1093/jpepsy/jsv100

23. Gouge N, Polaha J, Rogers R, Harden A. Integrating behavioral health into pediatric primary care: implications for provider time and cost. South Med J. 2016;109(12):774-778. doi:10.14423/ SMJ.0000000000000564

24. Kearney JA, Salley CG, Muriel AC. Standards of psychosocial care for parents of children with cancer. Pediatr Blood Cancer. 2015;62 (S5):S632-S683. doi:10.1002/pbc.25761

25. Dunning DL, Griffiths K, Kuyken W, et al. Research review: the effects of mindfulness-based interventions on cognition and mental health in children and adolescents - a meta-analysis of randomized controlled trials. J Child Psychol Psychiatry Allied Discip. 2019. doi:10.1111/jcpp. 12980 
26. Yang C-H, Conroy DE. Momentary negative affect is lower during mindful movement than while sitting: an experience sampling study. Psychol Sport Exerc. 2018;37:109-116. doi:10.1016/j. psychsport.2018.05.003

27. Bluth M, Thomas R, Cohen C, Bluth A, Goldberg RE. Martial arts intervention decreases pain scores in children with malignancy. Pediatric Health Med Ther. 2016;Volume 7:79-87. doi:10.2147/ PHMT.S104021

28. Alderfer MA, Long KA, Lown EA, et al. Psychosocial adjustment of siblings of children with cancer: a systematic review. Psychooncology. 2010;19(8):789-805. doi:10.1002/pon.1638

29. Vermaes IPR, Van Susante AMJ, Van Bakel HJA. Psychological functioning of siblings in families of children with chronic health conditions: a meta-analysis. J Pediatr Psychol. 2012;37(2):166-184. doi:10.1093/jpepsy/jsr081

30. Guite JW, Lobato DJ, Shalon L, Plante W, Kao BT. Pain, disability, and symptoms among siblings of children with functional abdominal pain. $J$ Dev Behav Pediatr. 2007;28(1):2-8. doi:10.1097/ DBP.0b013e3180307c26

31. de Vignemont F, Jacob P. What is it like to feel another's pain? Philos Sci. 2012;79(2):295-316. doi:10.1086/664742

32. Rosenberg AR, Postier A, Osenga K, et al. Long-term psychosocial outcomes among bereaved siblings of children with cancer. J Pain Symptom Manage. 2015;49(1):55-65. doi:10.1016/j. jpainsymman.2014.05.006

33. King S, Chambers CT, Huguet A, et al. The epidemiology of chronic pain in children and adolescents revisited: a systematic review. Pain 2011;152(12):2729-2738. doi:10.1016/j.pain.2011.07.016

34. Merikangas KR, He J-P, Burstein M, et al. Lifetime prevalence of mental disorders in U.S. adolescents: results from the National Comorbidity Survey replication-Adolescent supplement (NCS-A). J Am Acad Child Adolesc Psychiatry. 2010;49(10):980-989. doi:10.1016/j.jaac.2010.05.017

35. Long KA, Lehmann V, Gerhardt CA, Carpenter AL, Marsland AL, Alderfer MA. Psychosocial functioning and risk factors among siblings of children with cancer: an updated systematic review. Psychooncology. 2018. doi:10.1002/pon.4669

36. Bulloch B, Garcia-Filion P, Notricia D, Bryson M, McConahay T. Reliability of the color analog scale: repeatability of scores in traumatic and nontraumatic injuries. Acad Emerg Med. 2009. doi:10.1111/j.1553-2712.2009.00404.x

37. Wong D, Baker C. Pain in children: comparison of assessment scales. Pediatr Nurs. 1988;14(1):9-17.

38. Trentacosta CJ, Harper FWK, Albrecht TL, Taub JW, Phipps S, Penner LA. Pediatric cancer patients' treatment-related distress and longer-term anxiety: an individual differences perspective. $J$ Dev Behav Pediatr. 2016;37(9):753-761. doi:10.1097/ DBP.0000000000000327

39. Sharpe D, Rossiter L. Siblings of children with a chronic illness: a meta-analysis. J Pediatr Psychol. 2002. doi:10.1093/jpepsy/27.8.699

40. Zeltzer LK, Dolgin MJ, Sahler OJZ, et al. Sibling adaptation to childhood cancer collaborative study: health outcomes of siblings of children with cancer. Med Pediatr Oncol. 1996. doi:10.1002/(SICI) 1096-911X(199608)27:2<98::aid-mpo6>3.0.CO;2-O
41. Hedström M, Haglund K, Skolin I, Von Essen L. Distressing events for children and adolescents with cancer: child, parent, and nurse perceptions. J Pediatr Oncol Nurs. 2003;20(3):120-132. doi:10.1053/ jpon. 2003.76

42. Myrvik MP, Burks LM, Hoffman RG, Dasgupta M, Panepinto JA. Mental health disorders influence admission rates for pain in children with sickle cell disease. Pediatr Blood Cancer. 2013;60 (7):1211-1214. doi:10.1002/pbc.24394

43. Pate JT, Blount RL, Cohen LL, Smith AJ. Childhood medical experience and temperament as predictors of adult functioning in medical situations. Child Health Care. 1996;25(4):281-298. doi:10.1207/ s15326888chc2504_4

44. Bai J, Harper F, Penner L. Trajectories of procedure-related distress in children with cancer: risk factors and impact of persistent distress on long-term quality of life. Pediatr Blood Cancer. 2017;64:96.

45. Woolf CJ, Salter MW. Neuronal plasticity: increasing the gain in pain. Science (80-). 2000. doi:10.1126/science.288.5472.1765

46. Khaleel M, Puliyel M, Shah P, et al. Individuals with sickle cell disease have a significantly greater vasoconstriction response to thermal pain than controls and have significant vasoconstriction in response to anticipation of pain. Am J Hematol. 2017. doi:10.1002/ ajh. 24858

47. Kyngäs H, Mikkonen R, Nousiainen E-M, et al. Coping with the onset of cancer: coping strategies and resources of young people with cancer. Eur J Cancer Care (Engl). 2001;10(1):6-11. doi:10.1046/ j.1365-2354.2001.00243.x

48. Zeltzer LK, Recklitis C, Buchbinder D, et al. Psychological status in childhood cancer survivors: a report from the childhood cancer survivor study. J Clin Oncol. 2009;27(14):2396-2404. doi:10.1200/ JCO.2008.21.1433

49. Zegaczewski T, Chang K, Coddington J, Berg A. Factors related to healthy siblings' psychosocial adjustment to children with cancer: an integrative review. J Pediatr Oncol Nurs. 2016;33(3):218-227. doi:10.1177/1043454215600426

50. Horwitz WA, Kazak AE. Family adaption to childhood cancer: sibling and family systems variables. $J$ Clin Child Psychol. 1990;19:221-228. doi:10.1207/s15374424jccp1903_4

51. Haraldstad K, Sørum R, Eide H, Natvig GK, Helseth S. Pain in children and adolescents: prevalence, impact on daily life, and parents' perception, a school survey. Scand J Caring Sci. 2011;25 (1):27-36. doi:10.1111/j.1471-6712.2010.00785.x

52. Hoftun G, Romundstad PR, Rygg M. Factors associated with adolescent chronic non-specific pain, chronic multisite pain, and chronic pain with high disability: the Young-HUNT Study 2008. J Pain. 2012;13(9):874-883. doi:10.1016/j.jpain.2012.06.001

53. Roth-Isigkeit A, Thyen U, Stöven H, Schwarzenberger J, Schmucker P. Pain among children and adolescents: restrictions in daily living and triggering factors. Pediatrics. 2005. doi:10.1542/ peds.2004-0682

54. Haraldstad K, Christophersen K-A, Helseth S. Health-related quality of life and pain in children and adolescents: a school survey. $B M C$ Pediatr. 2017;17(1). doi:10.1186/s12887-017-0927-4

55. Deavin A, Greasley P, Dixon C. Children's perspectives on living with a sibling with a chronic illness. Pediatrics. 2018;142(2): e20174151. doi:10.1542/peds.2017-4151 


\section{Publish your work in this journal}

The Journal of Pain Research is an international, peer reviewed, open access, online journal that welcomes laboratory and clinical findings in the fields of pain research and the prevention and management of pain. Original research, reviews, symposium reports, hypothesis formation and commentaries are all considered for publication. The manuscript management system is completely online and includes a very quick and fair peer-review system, which is all easy to use. Visit http:// www.dovepress.com/testimonials.php to read real quotes from published authors. 